\title{
Growth and Division of Some Unicellular Blue-green Algae
}

\author{
By MARY MENNES ALLEN AND R. Y. STANIER \\ Department of Bacteriology and Immunology, University of California, \\ Berkeley, California, U.S.A. \\ (Accepted for publication 25 September 1967)
}

\begin{abstract}
SUMMAR Y
The growth of microcolonies of six strains of unicellular blue-green algae was studied by time-lapse photomicrography. The four rod-shaped strains divided regularly in a plane perpendicular to the long axis of the cell; one spherical strain divided successively in two planes, and one in three planes, perpendicular to one another.

Anacystis nidulans and the other rod-shaped blue-green algae studied have a very restricted ability to form chains, four-celled elements being the longest ones observed in slide cultures. They are therefore unicellular organisms, in no way different with respect to development from rod-shaped unicellular bacteria. The recent proposal that $A$. nidulans is filamentous and should be reclassified in the genus Phormidium is based on a mis-understanding of the nature of unicellularity among procaryotic organisms.
\end{abstract}

\section{INTRODUCTION}

The classification of the unicellular blue-green algae of the family Chroococcaceae is at present controversial. Natural-historical studies have led to the description of a very large number of form genera and species: more than 20 genera and 200 species were recognized in the compilatory work of Geitler (I932). In I956, Drouet \& Daily proposed a greatly simplified taxonomic treatment of the group, largely based on an exhaustive comparison of published descriptions and herbarium specimens; they recognized only six genera and 18 species. Their treatment is, however, not accepted by others (Geitler, I960; Skuja, I956).

The simplified generic subdivision of Drouet \& Daily (1956) lays major emphasis on the planes of successive cell divisions; but the authors do not mention how this developmental character can be reliably determined by the examination of herbarium specimens. A more fundamental taxonomic ambiguity is revealed by the nomenclatural history of a rod-shaped strain which was purified by Kratz \& Allen, and identified originally by Drouet as Anacystis nidulans (Kratz \& Myers, I955). This supposedly unicellular organism has since been maintained in many culture collections, and used for various experimental studies. According to Silva (I962), Drouet has more recently re-identified it as Phormidium mucicola (family Oscillatoriaceae) on the basis of its ability to form short filaments. This implies that even the familial and ordinal assignment of a blue-green alga is not easily made in some instances.

It should be noted that the classification of this group has not so far been based on the comparative study of pure cultures, grown under reasonably well-controlled conditions. We describe here the growth of Anacystis nidulans (strain of Kratz \& Allen) 
and of five other unicellular blue-green algae, as determined with pure strains examined in slide cultures. Our purpose was to ascertain whether the mode of division is a constant and easily determinable strain property, as implied by the taxonomic treatment of Drouet \& Daily (1956); and whether $A$. nidulans and other rod-shaped strains can be most appropriately characterized as 'unicellular' or 'filamentous'.

\section{METHODS}

Organisms. Four rod-shaped and two spherical strains were examined (Table 1). Strains 6307 and 6308 were uni-algal when received, and were freed from bacteria by us. Strain 630I (Anacystis nidulans of Kratz \& Allen) was received as a pure culture. The other three strains were isolated from nature and purified by us.

Cultivation. Cultures were maintained in tubes of the liquid medium of Hughes, Gorham \& Zehnder (1958), modified by increasing the concentration of $\mathrm{NaNO}_{3}$ to I. $5 \mathrm{~g}$. $/ 1$. The tubes were incubated at $30^{\circ}$ in a water bath illuminated laterally with fluorescent lights (intensity at entrance window: $500 \mathrm{ft}$.-candles).

Table I. Unicellular blue-green algae examined

\begin{tabular}{cll} 
Strain & \multicolumn{1}{c}{ Source } & \multicolumn{1}{c}{ Size and shape } \\
6301 & Anacystis nidulans* & Rods, $2 \cdot 0 \times 0.8 \mu$ \\
6307 & Coccochloris peniocystis $\dagger$ & Rods, $1 \cdot 3 \times 0.8 \mu$ \\
6311 & Local isolate from water & Rods, $2.0 \times 1 \cdot 3 \mu$ \\
6312 & Local isolate from water & Rods, $2.7 \times 1 \cdot 3 \mu$ \\
6308 & Gleocapsa alpicola $\dagger$ & Spheres, $3.4 \mu$ diameter \\
6501 & Local isolate from water & Spheres, $6.8 \mu$ diameter, \\
& & heavy laminate sheath
\end{tabular}

* Strain of Kratz and Allen, obtained from Dr M. B. Allen, Kaiser Foundation Research Institute, Richmond, California.

† Obtained from Dr G. P. Fitzgerald, University of Wisconsin, Madison, Wisconsin.

Slide cultures were prepared as follows. A drop of medium containing Difco agar $(\mathrm{I} \%, \mathrm{w} / \mathrm{v})$ was spread in a thin film over an area of $2.5 \times \mathrm{I} .8 \mathrm{~cm}$. on a sterile slide and allowed to solidify. A small drop of a liquid culture was placed on the surface of the agar, two small drops of sterile liquid medium were deposited adjacent to the agar patch, and a sterile coverslip $(2.4 \times 6.0 \mathrm{~cm}$.) gently lowered on to the agar surface, the edges then being sealed with sterile Vaseline + paraffin $(I+I)$. The slide was examined microscopically, and a suitable field for observation selected. The sealed slide was illuminated continuously by two lateral fluorescent lights (intensity at microscope stage: $500 \mathrm{ft}$.-candles). The growing microcolonies were photographed at intervals with dark-phase contrast illumination.

\section{RESULTS}

Plate I shows the development of microcolonies of Kratz \& Allen's strain of Anacystis nidulans (630I) on a slide culture over a period of $44 \mathrm{hr}$, corresponding to approximately three generations of growth. The development of the other rod-shaped strains $(6307,6311,6312)$ in slide cultures was similar. Successive divisions took place regularly in planes perpendicular to the long axis of the cell. Although daughter cells 
tended to remain associated for a short period following completion of division, the chains produced were never more than four cells in length, since slippage after division caused frequent disorientations.

Plate 2 shows the development of strain 6308 (Gleocapsa alpicola) on a slide culture over a period of $36 \mathrm{hr}$, corresponding to approximately three generations. The cells of this strain are spherical, and not enclosed by a sheath. Division occurred in two planes at right angles to one another; but regular tetrads did not persist, as a result of slight shiftings of the daughter cells in the growing colony.

Plate 3 shows the growth of strain $650 \mathrm{I}$ in slide culture over a period of nearly $8 \mathrm{o} \mathrm{hr}$, corresponding to nearly three generations. The spherical cells of this strain were held together in small colonies by a multi-layered sheath, new layers of which were formed at each generation. Reproduction occurred by rupture of the oldest, outer, layer of the sheath through pressure of the growing colony. The sequence shown in Pl. 3 starts with a flat 4-celled colony, consisting of two pairs of recently divided cells: the disposition of the cells and sheath layers indicates that the two preceding divisions had occurred at right angles to one another. The first observed division $(24 \mathrm{hr})$ took place in a third plane, at right angles to the two preceding planes, to yield a three-dimensional, 8-celled colony. The lower layer of 4 cells is indistinct, since it lies somewhat below the plane of focus. Thereafter, constriction by the sheath caused marked displacements of the enclosed cells $(34,46,57,75 \mathrm{hr})$ so that the plane of the next division could not be precisely determined. After $79 \mathrm{hr}$ the colony had become somewhat flattened, as a result of the rupture of the outer layers of the sheath: the lower 8 cells (derived from the lower pair of cells in the first figure of the sequence) are all clearly visible, in the course of a well-synchronized division.

\section{DISCUSSION}

The four rod-shaped strains examined multiply by regular binary transverse fission. Attachment between daughter-cells is evidently weak, since even on an agar surface, where the preservation of attachment is favoured, 4-celled chains are the longest elements observed. All these organisms, including the Kratz \& Allen strain of Anacystis nidulans, show a mode of growth and reproduction that is not significantly different from that of rod-shaped unicellular eubacteria. We cannot therefore accept the contention that they are filamentous blue-green algae, in the sense that an Oscillatoria, with its many-celled structure and hormogonial mode of reproduction, can be described as 'filamentous'. The proposed reassignment of $A$. nidulans to the genus Phormidium (Silva, 1962) is evidently based on a misunderstanding of the cellular condition of a growing rod-shaped procaryotic organism, aptly characterized by Robinow (1945) as 'two-cells-about-to-become-four'.

In contrast to the rod-shaped strains, both the spherical strains that we have examined divide in more than one plane. Strain 6308 divides in two planes at right angles to one another, and strain $650 \mathrm{I}$ in three planes at right angles to one another. However, post-divisional changes of cellular orientation can completely obscure the relations between successive planes of division in both these strains. Hence a distinction between genera based on the number and relation of successive planes of division, as proposed by Drouet \& Daily (1956), may well lead to determinative difficulties, particularly when identifications are attempted on natural material without cultural 
studies. The possible taxonomic value of this character can be adequately assessed only by developmental studies on a large number of spherical strains.

The determinative ambiguities of the traditional form genera appear even more serious. The successive forms assumed by a growing colony of strain 650I (Pl. 3) might justify assignment to several form genera recognized by Geitler (1932): e.g. Chroococcus, Microcystis, Gleocapsa or Aphanocapsa. Furthermore, in terms of divisional behaviour (rather than ultimate colony form) strain 6308 (Pl. 2) can be related to the genus Merismopedia, in which the spherical cells are disposed in flat arrays of tetrads, while strain 650 I can be related to the genus Eucapsis, in which the spherical cells are arranged in cubical packets. In our judgement, a binary subdivision of the Chroococcaceae into two form genera (rods and spheres) would constitute the most useful temporary taxonomic solution. Eventually, a more elaborate subdivision of the group may become possible; but it will not have a solid scientific basis until really extensive comparative studies with pure cultures have been carried out.

This work was supported by a United States Public Health Service Predoctoral Fellowship (I-F I-GM-2I, 008-OI) to Mary Mennes Allen, and by a grant from the National Science Foundation (GB-4II2) to R. Y. Stanier.

\section{REFERENCES}

Drouet, F. \& DaILy, W. A. (1956). Revision of the coccoid myxophyceae. Butler Univ. bot. Stud. I2, 1 .

GeITLER, L. (1932). Cyanophyceae. In Rabenhorts's Kryptogamenflora von Deutschland, Österreich und der Schweiz. vol. 14, p. I.

Geitler, L. (1960). Schizophyceen. In Handbuch der Pfanzenanatomie. 2nd. ed., vol. 6 (I), p. 87.

Hughes, E. O., Gorham, P. \& Zehnder, A. (1958). Toxicity of a unialgal culture of Microcystis aeruginosa. Can. J. Microbiol. 4, 225.

Kratz, W. A. \& MYers, J. (1955). Nutrition and growth of several blue-green algae. Am. J. Bot. 42, 282.

Robinow, C. F. (1945). Addendum to R. J. Dubos, The Bacterial Cell, p. 370. Cambridge, Mass.: Harvard University Press.

Silva, P. C. (1962). Classification of algae. In Physiology and Biochemistry of Algae, ed. by

R. A. Lewin, footnote, p. 834. New York: Academic Press.

Skuja, H. (1956). Review. Svensk. Bot. Tidskr. 50, 550.

\section{EXPLANATION OF PLATES}

\section{Plate I}

A series of time-lapse photomicrographs illustrating the growth of a rod-shaped unicellular bluegreen alga, Anacystis nidulans strain 630I, in an illuminated slide culture. The numbers on each figure indicate hours after the preparation of the slide culture. Dark phase-contrast. $\times 1250$.

\section{Plate 2}

A series of time-lapse photomicrographs illustrating the growth of a coccoid unicellular bluegreen alga, Gleocapsa alpicola strain 6308, in an illuminated slide culture. The numbers on each figure indicate hours after the preparation of the slide culture. Dark phase-contrast. $\times 1250$.

\section{Plate 3}

A series of time-lapse photomicrographs illustrating the growth of an unidentified ensheathed, coccoid, unicellular blue-green alga, strain 650I. The numbers on each figure indicate hours after the preparation of the slide culture; pairs of figures bearing the same number represent photomicrographs taken after the same time interval, but in different focal planes. Dark phase-contrast. $\times 750$. 
Journal of General Microbiology, Vol. 5I, No. 2

Plate I
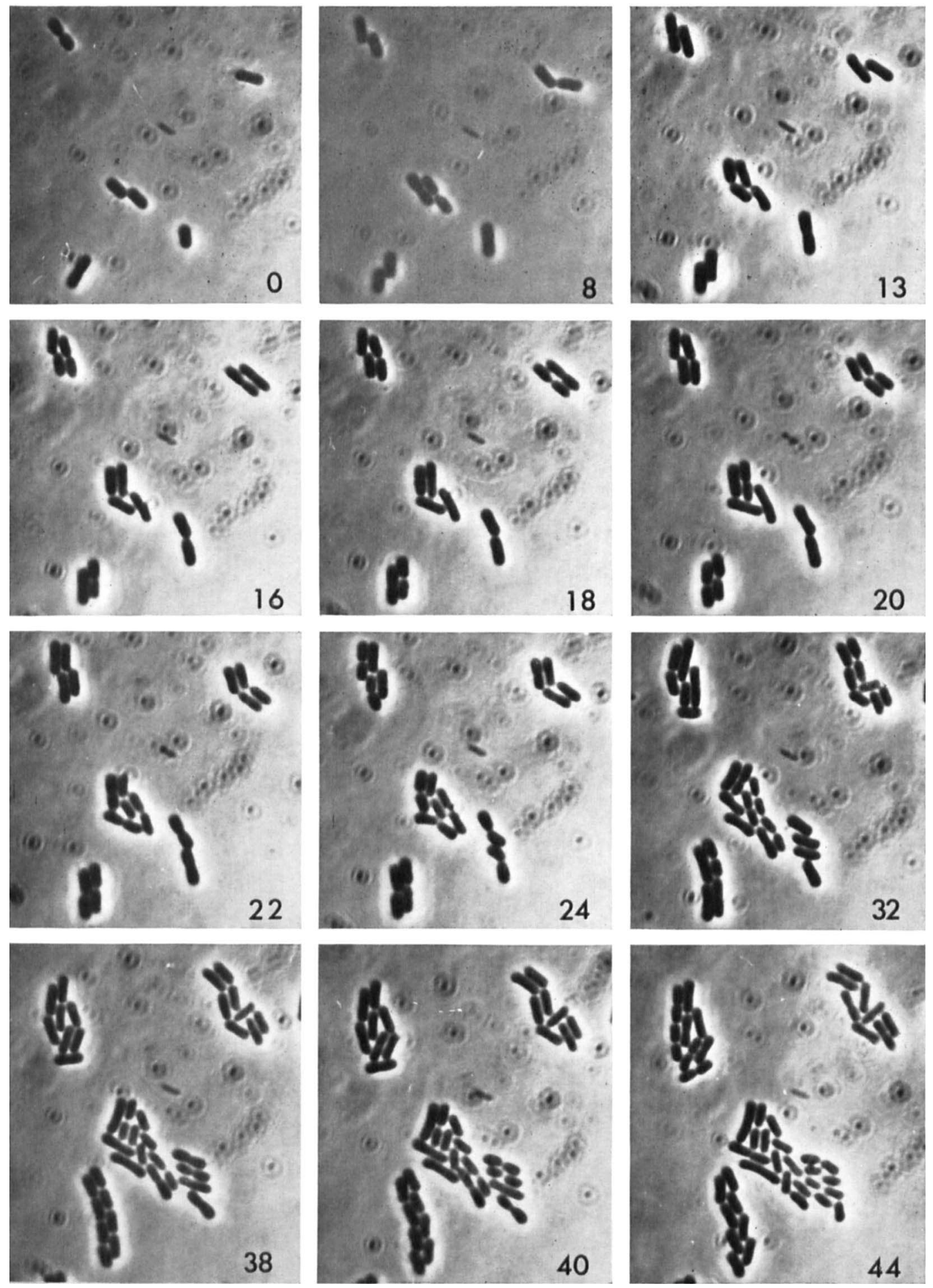

M. M. ALLEN AND R. Y. STANIER

(Facing p. 202) 
Journal of General Microbiology, Vol. 5I, No. 2

Plate 2
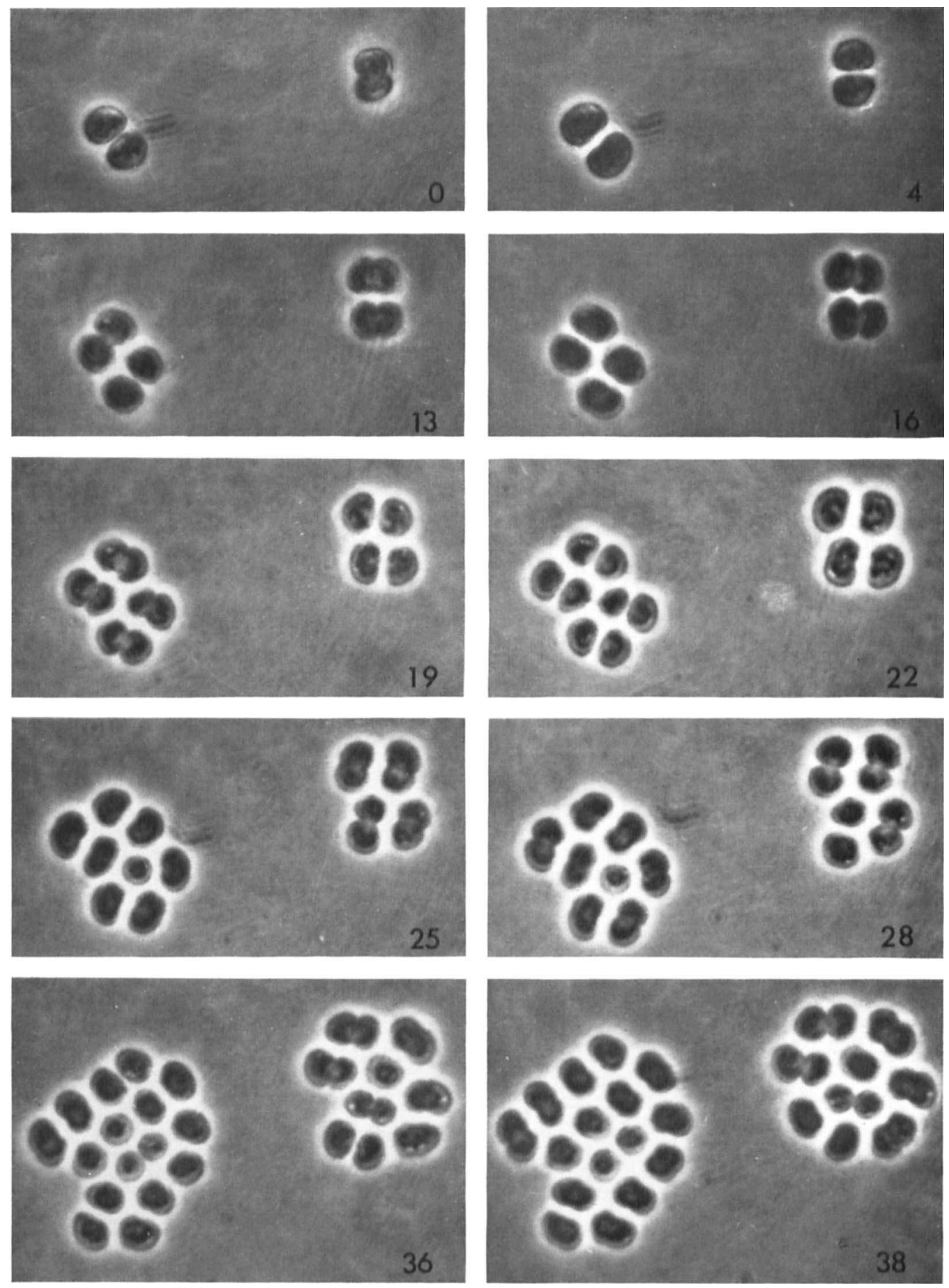

M. M. ALLEN AND R. Y. STANIER 

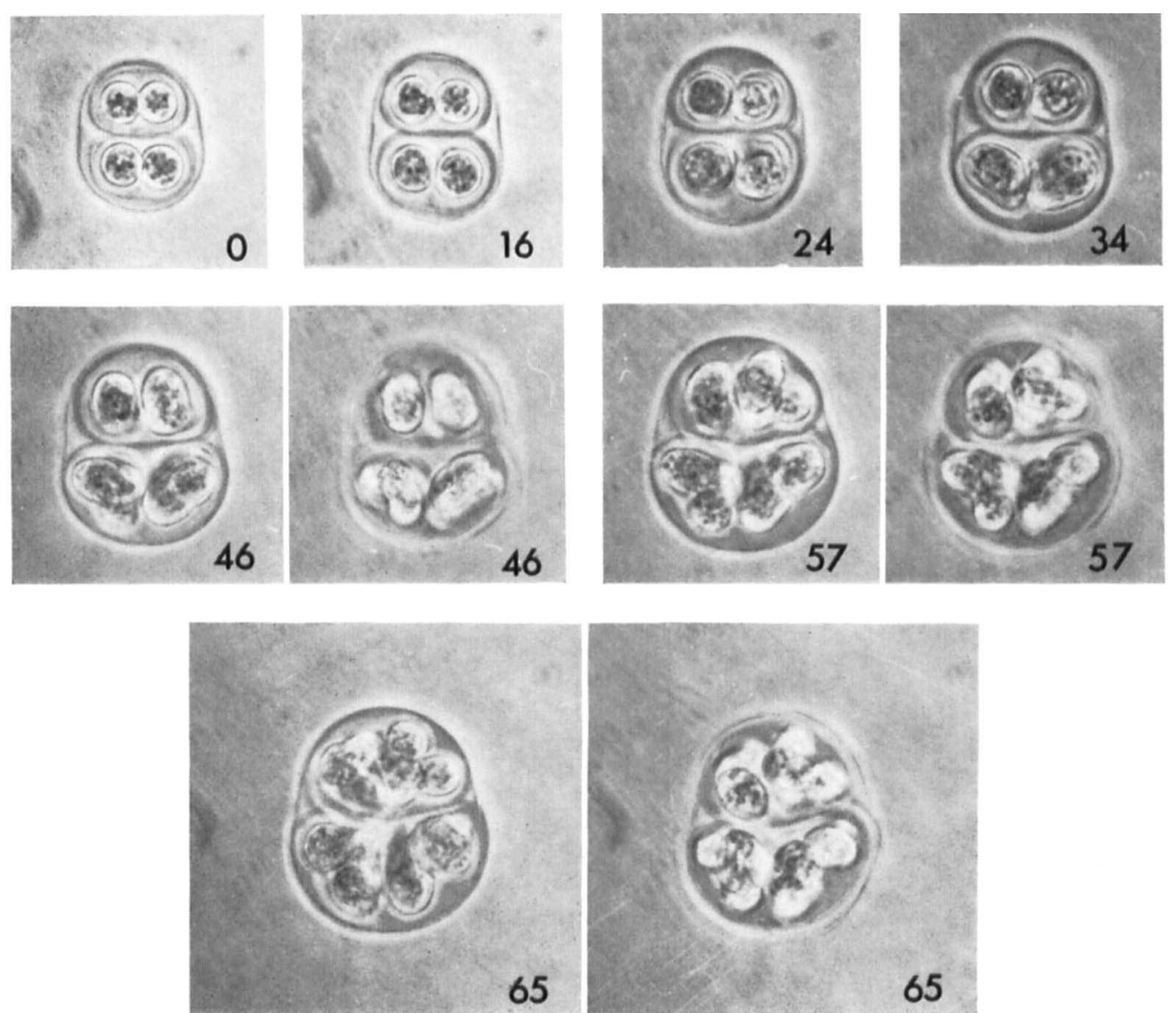

65
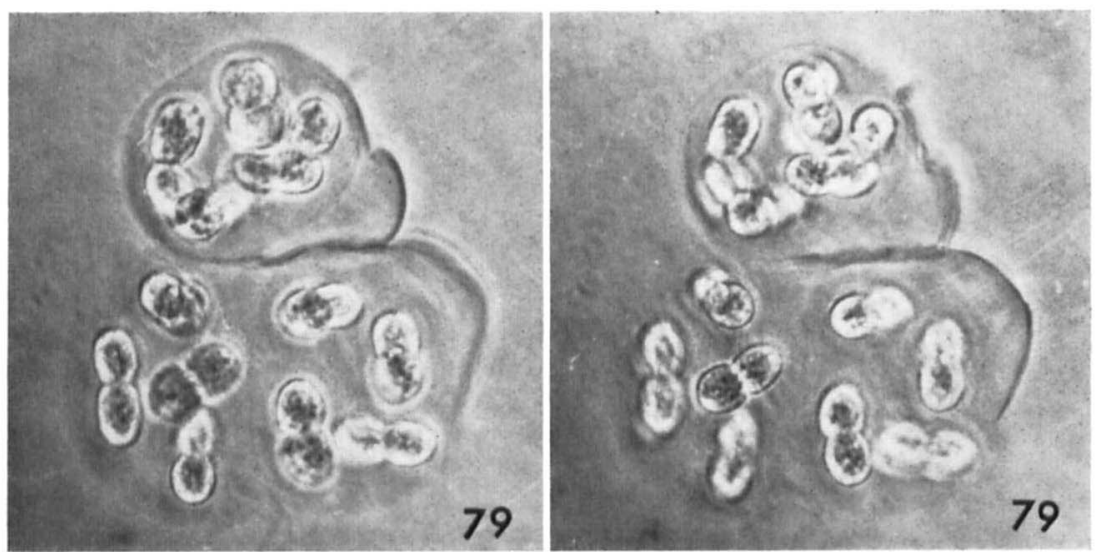

M. M. ALLEN AND R. Y. STANIER 